\title{
A INFLUÊNCIA DA COBERTURA DAS EMPRESAS DE RATING SOBRE O GERENCIAMENTO DE RESULTADOS DAS COMPANHIAS ABERTAS BRASILEIRAS
}

\author{
CAMILA VASCONCELOS \\ Graduada em Ciências Contábeis pela \\ Universidade Presbiteriana Mackenzie \\ E-mail: \\ IVAN MIYASHIRO \\ Graduado em Ciências Contábeis pela \\ Universidade Presbiteriana Mackenzie \\ E-mail: ivan@poit.com.br
}

\author{
DENILSON REIS \\ Graduado em Ciências Contábeis pela \\ Universidade Presbiteriana Mackenzie \\ E-mail: denilson.reis@uol.com.br \\ EDILSON PAULO \\ Doutor em Ciências Contábeis pela Universidade de São Paulo \\ Professor do Programa Multiinstitucional e Interregional de \\ Pós-Graduação em Ciências Contábeis UnB, UFPB e UFRN \\ E-mail: e.pauulo@uol.com.br
}

\section{Resumo}

Estudos anteriores apresentam evidências empíricas da influência das atividades dos analistas financeiros sobre o comportamento oportunístico dos gestores em relação aos números contábeis, porém, nenhum desses trabalhos pesquisou a influência das empresas de rating sobre as informações contábeis. Diante da relevância desses intermediários da informação no mercado financeiro, tem-se o seguinte problema de pesquisa: o gerenciamento de resultados contábeis das companhias brasileiras é afetado pela cobertura das empresas de rating? 0 objetivo principal deste trabalho foi analisar a relação entre o comportamento discricionário dos gestores e a cobertura das empresas de rating. Este trabalho enquadra-se como uma pesquisa exploratória, utilizando-se, também, da pesquisa bibliográfica e empírica. A amostra estudo é formada pelo conjunto de companhias abertas brasileiras, compreendendo o período entre 1996 a 2006. Os modelos operacionais Jones e KS utilizados para mensurar os accruals discricionários são estimados através da abordagem pooling of independent cross sections. Os resultados desta pesquisa evidenciam que não existe relação significativa entre os accruals discricionários e a cobertura das empresas de rating, sugerindo que o gerenciamento de resultados não é afetado pela cobertura das empresas de rating no mercado brasileiro.

Palavras-chave: manipulação das informações contábeis; rating; gerenciamento de resultados contábeis.

\begin{abstract}
Previous studies show empirical evidences of the influence of financial analysts activities about opportunistic behavior of the managers in relation to accounting numbers. However, none of these studies had researched the influence of rating companies about accounting information. Facing the relevance of these information mediators in financial market, the problem of this research is: is managing accounting results of Brazilian Companies affected by rating companies' cover? The main objective of this work was to analyze the relation between discretionary managers' behavior and the cover of rating companies. This study is an exploratory work, and also uses bibliographical and empirical research. The study sample is formed by a set of Brazilian open companies from 1996 to 2006. Jones and KS operational models used to measure discretionary accruals are estimated through pooling of independent cross section approach. The results evidence that there is no significant relation between discretionary accruals and rating companies cover, what suggests that results management is not affected by rating companies cover in Brazilian market.
\end{abstract}

Key words: manipulation of accounting information; rating; management accounting results. 


\section{INTRODUÇÃO}

Freqüentemente, os investidores não têm informação (ou capacidade) para escolher os melhores investimentos e, por essa razão, confiam nos intermediários da informação para auxiliá-los na tomada de decisões de investimentos e financiamentos (PALEPU, HEALY \& BERNARD, 2004). Entre os principais intermediários da informação nos diversos mercados financeiros estão a Contabilidade, a auditoria independente, os analistas financeiros, os bancos de investimentos e as empresas de classificação de rating, que auxiliam na redução da assimetria informacional e, portanto, têm um papel relevante no sistema de governança corporativa e na eficiência do mercado de capitais.

Beaver (1998, p. 10) apresenta três atividades exercidas pelos intermediários da informação:

a. Busca pela informação privada: refere-se à procura por informações que não estão publicamente disponíveis;

b. Análise prospectiva: refere-se ao processamento, análise e interpretação da informação para predição;

c. Análise retrospectiva: refere-se à interpretação de eventos depois do fato ocorrido.

Pode-se considerar que a Contabilidade e as atividades dos analistas financeiros (ligados ou não a bancos de investimentos e empresas de rating) são complementares. Os analistas facilitam a interpretação e a disseminação da informação contábil, enquanto um melhor nível de informação aumenta a acurácia das previsões dos analistas e, conseqüentemente, afeta positivamente as suas recomendações. Por outro lado, as atividades dos analistas financeiros cobrem algumas limitações do sistema contábil, o que leva alguns pesquisadores (BEAVER, 1998; HEALY \& PALEPU, 2001; PALEPU, HEALY \& BERNARD, 2004) a considerá-los como concorrentes da Contabilidade.

Os bancos de investimentos fornecem seus serviços de consultoria financeira para auxiliar as empresas na captação de recursos no mercado de capitais (PALEPU, HEALY e BERNANRD, 2004). Já as empresas de rating avaliam os riscos que podem impactar no retorno dos investimentos em títulos de dívidas por meio de informações disponíveis sobre a empresa emissora e elaboram uma classificação de riscos. Segundo Fortuna (2005, p. 514), "o rating é importante porque é uma forma rápida de um investidor poder comparar as diferentes alternativas de investimento e decidir onde aplicar". Porém, cabe destacar que o rating não é uma recomendação de investimento e sim uma opinião sobre a capacidade futura de cumprimento de suas obrigações no período esperado, portanto, está relacionada ao risco de crédito.

Entretanto, Healy e Papelu (2001) alertam que os relatórios dos analistas financeiros, bancos de investimentos e empresas de rating, apesar de adicionar valor ao mercado de capitais, também são considerados intermediários imperfeitos da informação, em parte por conta dos conflitos de interesses e por exercerem pressão excessiva sobre a administração.

Como esses intermediários da informação monitoram o desempenho das companhias para suportar as recomendações de investimentos feitas aos seus clientes, conseqüentemente, eles pressionam os administradores dessas empresas que observam suas previsões e recomendações. Por outro lado, existem pressões sobre os analistas para atingir os desejos dos investidores e, por isso, tais profissionais necessitam manter boas relações com a administração para acessar a informações privadas, além da necessidade de evitar a degradação dos títulos investidos, nos quais os seus principais clientes têm significativos investimentos (YU, 2005). Por exemplo, algumas pesquisas evidenciam que os 
analistas financeiros são super-otimistas sobre novas emissões de títulos e valores mobiliários (RAJAN \& SERVAES, 1997; TEOH \& WONG, 1997).

Segundo Yu (2005), os analistas afetam o fluxo de informações das corporações e, conseqüentemente, a discricionariedade dos administradores nos números contábeis. Diversos estudos realizados apresentam evidências de práticas de gerenciamento de resultados contábeis (JONES, 1991; MARTINEZ, 2001). Algumas dessas pesquisas, especificamente, estudam a influência das atividades dos analistas financeiros sobre o desempenho dos números contábeis das firmas analisadas (YU, 2005; PAULO, LIMA \& LIMA, 2006). Mas, apesar da relevância, não existem trabalhos que avaliem a influência das atividades desenvolvidas pelas empresas de classificação de rating na informação contábil.

Assim, sugere-se o seguinte problema de pesquisa: o gerenciamento de resultados contábeis das companhias brasileiras é afetado pela cobertura das empresas de rating? 0 objetivo principal deste trabalho foi analisar a relação entre o comportamento discricionário dos gestores e a cobertura das empresas de rating.

Este trabalho caracteriza-se como uma pesquisa exploratória que se destinou a buscar conhecimentos mais concretos, incorporando características não claramente explícitas, bem como procurando dimensões não conhecidas e que necessitem ser mais compreendidas neste ramo do conhecimento (BEUREN, 2003). Também é caracterizada como uma pesquisa bibliográfica, porque por meio do referencial teórico atual, buscou-se conhecer, analisar e interpretar as contribuições científicas existentes sobre o tema, principalmente, em livros, teses, dissertações e artigos, nacionais e internacionais.

Utilizou-se, também, a abordagem empírica através da aplicação de alguns dos modelos econométricos descritos na literatura específica, para verificar se existem diferenças de comportamento discricionário nas companhias abertas brasileiras diante da cobertura pelas empresas de rating. As informações necessárias para a pesquisa foram obtidas do banco de dados da Economática e empresas de rating que atuam no mercado brasileiro.

\section{REVISÃO DE LITERATURA}

\subsection{INFORMAÇÕES CONTÁBEIS E OS ANALISTAS FINANCEIROS}

O sistema de governança corporativa tornou-se um dos temas mais relevantes nos últimos tempos no meio empresarial, principalmente, após o aumento do número de grandes corporações envolvidas em escândalos financeiros ocorridos nos Estados Unidos, como, por exemplo, Enron, Worldcom e Xerox.

Esses acontecimentos podem ser explicados pela teoria contratual, que se baseia na idéia de que a firma é um anexo de contratos entre clientes, trabalhadores, executivos e fornecedores de material e capital. Porém, ocorrem muitos eventos que não estão previstos nesses contratos (as contingências), deixando espaço para a necessidade de tomada de decisão por parte dos gestores (JENSEN, 2001, p.1).

Diante da possibilidade, as escolhas dos gestores podem ser pautadas por interesses pessoais, o que ocasionará conflitos de agência. Dentro desse contexto, a Contabilidade tem papel importante, pois fornece uma fonte significativa de informações para os mecanismos de governança, auxiliando na moderação dos problemas de agência. 
Segundo Beaver $(1998$, p.50) é possível identificar algumas conseqüências econômicas relevantes da informação contábil, particularmente, para acionistas:

a. A informação contábil pode afetar a distribuição de riqueza entre investidores. Essa conseqüência decorre do fato de que investidores mais bem informados podem aumentar sua riqueza à custa de investidores menos informados;

b. A informação contábil pode afetar a percepção dos coeficientes de risco e sua distribuição entre os agentes econômicos;

c. A informação contábil pode afetar as taxas de investimento e consumo em toda a sociedade;

d. A informação contábil pode afetar a forma pela quais os investimentos são alocados entre empresas.

Conforme Silva (2006), considera-se o analista do mercado de capitais um profissional dedicado à avaliação sistemática de alternativas de investimentos em valores mobiliários, visando fornecer o adequado suporte técnico aos demais integrantes do mercado quanto aos elementos risco e retorno esperado. Para esses analistas, não somente as informações contábeis são importantes, como também toda informação ligada ao negócio da empresa.

Os analistas financeiros (de bancos de investimentos ou de empresas de rating) precisam captar as informações e transformá-las em ferramentas de decisão. Quanto maior e melhor o nível de informação, maiores as probabilidades de emitir uma opinião acertada. As informações utilizadas pelos analistas financeiros são, principalmente, aquelas fornecidas pela Contabilidade (PALEPU \& HEALY, 1996).

As notas dadas pelas empresas de rating são informações importantes no mercado de capitais, pois influenciam a tomada de decisão dos investidores. Para que se possa dar essa nota, os analistas financeiros da empresas de rating interagem com a administração da empresa e questionam os diferentes aspectos dos números contábeis apresentados. Assim, alguns administradores sentem-se pressionados pelas previsões e recomendações dos analistas financeiros.

Mas, como comentado anteriormente, devido às pressões sofridas ou exercidas sobre a administração das empresas, os analistas financeiros são considerados intermediários imperfeitos da informação, por conta dos conflitos de interesses.

\subsection{A INFORMAÇÃO CONTÁBIL E O GERENCIAMENTO DE RESULTADOS CONTÁBEIS}

A informação contábil é influenciada pela existência de critérios alternativos de mensuração e evidenciação, fazendo com que o administrador possa escolher dentre as normas e práticas permitidas pela regulação contábil, quando essa existir, pois podem ocorrer situações em que determinado evento ou transação econômica ainda não tenha norma especifica. Nesse caso, normalmente, as empresas buscam normas que especifiquem outro evento ou transação semelhante àquele que está sendo mensurado ou evidenciado.

Fields, Lys e Vincent (2001) afirmam que a natureza das escolhas contábeis inclui:

- escolha entre regras igualmente aceitas;

- julgamentos e estimativas requeridas por alguns sistemas contábeis;

- decisões de estratégias de disclosure; 
- decisões do momento do reconhecimento e

- atividades de lobby.

Isso possibilita que os administradores escolham alternativas válidas com o objetivo de apresentarem informações da forma desejada, impactando no desempenho econômico ou na estrutura financeira da empresa (FIELDS, LYS \& VINCENT, 2001). Portanto, a Contabilidade pode apresentar dificuldades em atingir os seus objetivos, em especial, a diminuição da assimetria informacional em certos ambientes institucionais e organizacionais. Mas, para Scott (2003), mesmo que os preços dos títulos no mercado reflitam totalmente toda a informação publicamente disponível, ainda provavelmente os insiders sabem mais do que os outsiders sobre a verdadeira qualidade da firma.

O amplo conjunto de critérios de mensuração e evidenciação contábil permite que os administradores escolham uma das alternativas válidas a fim de divulgarem os relatórios da forma desejada.

Gerenciamento de resultados ocorre quando os administradores usam julgamento sob a informação financeira e sobre as atividades operacionais para alterar informações financeiras, ou iludir alguns investidores sobre o desempenho econômico da companhia, ou para influenciar resultados contratuais que dependam dos números contábeis informados. (HEALY e WAHLEN, 1999, p. 368).

Scott (2003, p. 369) afirma que o "gerenciamento de resultados é a escolha por um administrador da política contábil de forma que atinja alguns objetivos específicos".

Martinez (2001) cita algumas causas que podem levar os executivos a ter comportamento oportunístico sobre os números contábeis:

a. 0 desejo de preservar o cargo, mesmo que isso implique comprometer a qualidade dos resultados contábeis apresentados;

b. A pressão dos acionistas por resultados cada vez maiores e melhores, bem como o anseio de atrair novos investidores e acionistas;

c. Reduzir variabilidade dos resultados contábeis;

d. Aumentar ou diminuir resultados contábeis;

e. A ambição de obter bônus significativos;

Segundo Beneish (2001), as pesquisas sobre gerenciamento de resultados baseados em accruals são mais comuns, pois o accrual é um componente não observado do resultado contábil e, conseqüentemente, é menos provável que os usuários possam detectar o efeito da manipulação das informações contábeis.

As acumulações (accruals) seriam todas aquelas contas de resultados que entraram no cômputo do lucro, mas não implicam necessariamente movimentação de disponibilidades, e que para a literatura internacional, seria a diferença entre o lucro líquido e o fluxo de caixa. (MARTINEZ, 2001, p. 16).

Porém, o accrual é um conceito contábil empregado para atender ao regime de competência (accruals basis) e que busca mensurar o resultado no sentido econômico, independentemente da realização financeira das transações e eventos. Segundo Martins (1999), com algumas exceções, a diferença entre accruals basis e cash basis (fluxo de caixa) é uma questão temporal.

Com o intuito de desenvolver uma metodologia para analisar o gerenciamento de resultados, tem-se necessidade de separar os accruals em: (1) accruals discricionários, que são artificiais e teriam como objetivo somente manipular o resultado contábil e; (2) accruals não-discricionários, que são inerentes às atividades da empresa. Para isso, alguns 
modelos operacionais de accruals agregados foram desenvolvidos, considerando que o componente discricionário seria uma proxy do gerenciamento de resultados (JONES, 1991; KANG; SIVARAMAKRISHNAN, 1995; MARTINEZ, 2001).

\section{METODOLOGIA}

\subsection{TIPO E MÉTODO DE PESQUISA}

O trabalho caracteriza-se como um estudo exploratório, pois buscou a obtenção de maiores conhecimentos sobre o comportamento dos accruals contábeis frente à cobertura dos analistas financeiros ligados às empresas de rating no mercado de capitais brasileiro. Consistentemente com o estudo de Paulo, Lima e Lima (2006), foi utilizada a abordagem empírica por meio da aplicação de alguns dos modelos econométricos descritos na literatura específica, para verificar se existem diferenças de comportamento discricionário nas companhias abertas brasileiras cobertas pelas empresas de rating.

\subsection{SELEÇÃO E COMPOSIÇÃO DA AMOSTRA}

A amostra inicial deste estudo foi composta pelas companhias abertas brasileiras. As informações necessárias para a pesquisa foram extraídas das dos bancos de dados da Comissão de Valores Mobiliários e da Economática, bem como das empresas de rating que atuam no mercado brasileiro, no período compreendido entre os anos de 1996 a 2006.

Foram feitas pesquisas em 04 das 06 empresas de rating que atuam no mercado brasileiro. As empresas de rating pesquisadas neste trabalho foram a Standard \& Poors, Moody's Investors, Fitch IBCA e Merril Lynch.

Devido às características dos modelos utilizados, foram excluídas da amostra as companhias abertas que exercem atividades financeiras e as de administração de empresas e empreendimentos ou que tenham receitas operacionais exclusivamente oriundas de participações societárias.

A amostra final foi composta por 3.051 empresas-ano pois, além das exclusões citadas anteriormente, observou-se a ausência de divulgação de dados necessários para a pesquisa.

\subsection{DEFINIÇÃO DOS MODELOS EMPREGADOS}

A estimação dos accruals discricionários (proxy de gerenciamento de resultados contábeis) foi realizada por meio dos modelos propostos por Jones (1991) e Kang e Sivaramakrishnan (1995). 
Jones (1991) propõe um modelo que busca controlar os efeitos das mudanças no ambiente econômico da firma sobre os accruals não-discricionários através da variação das receitas e do montante do imobilizado e diferido. Os accruals não-discricionários pelo modelo de Jones são calculados da seguinte forma (JONES, 1991, p. 211):

$$
N D A_{i t}=\alpha\left(\frac{1}{A_{t-1}}\right)+\beta_{1}\left(\Delta R_{i t}\right)+\beta_{2}\left(P P E_{i t}\right) \quad(\text { Equação 1) }
$$

em que:

$N D A_{i t} \quad=$ accruals não-discricionários da empresa $i$ no período $t$;

$\Delta R_{i t} \quad=$ variação das receitas líquidas da empresa $i$ do período $t-1$ para o período $t$, ponderada pelos ativos totais no final do período $t-1$;

$P P E_{i t} \quad=$ saldos das contas do Ativo Imobilizado e Ativo Diferido (bruto) empresa $i$ no final do período $t$, ponderados pelos ativos totais no final do período $t-1$;

$A_{i t-1} \quad=$ ativos totais da empresa no final do período $t-1$;

$a, B_{1}$ e $B_{2}=$ coeficientes estimados da regressão pela Equação 2. modelo:

As estimativas dos parâmetros dos modelos $a, B_{1}$ e $B_{2}$ são geradas pelo seguinte

$$
T A_{i t}=\alpha\left(\frac{1}{A_{t-1}}\right)+\beta_{1}\left(\Delta R_{i t}\right)+\beta_{2}\left(P P E_{i t}\right)+v_{i t} \quad(\text { Equação 2) }
$$

em que:

$T A_{i t}=$ accruals totais da empresa $i$ no período $t$, ponderados pelos ativos totais no final do período $t$ - 1 ;

$\Delta R_{i t} \quad=$ variação das receitas líquidas da empresa $i$ do período $t-1$ para o período $t$, ponderada pelos ativos totais no final do período $t-1$;

$P P E_{i t} \quad=$ saldos das contas Ativo Imobilizado e Ativo Diferido (bruto) da empresa $i$ no final do período $t$, ponderados pelos ativos totais no final do período $t-1$;

$A_{i t-1} \quad=$ ativos totais da empresa no final do período $t-1$.

$v_{i t} \quad=$ erro da regressão (resíduos).

O pressuposto assumido é que as variáveis $P P E$ e $\Delta R$ controlam os accruals nãogerenciados associados, respectivamente, às despesas com depreciação e amortização e mudanças das atividades econômicas da empresa (PEASNELL et al, 2000, p. 314). Jones (1991) considera que todos os accruals, excetuando aqueles relacionados à provisão de despesas com provisão de imposto de renda, devem ser considerados nos modelos de detecção de gerenciamento de resultados e que, ao incluir os ativos imobilizados como variáveis exploratórias, ele controla o tamanho da firma.

Espera-se que o coeficiente da variável PPE seja negativo, pois o nível do ativo imobilizado e diferido está relacionado ao decréscimo dos resultados por meio da apropriação (accruals) das despesas com depreciação e amortização. Por outro lado, o sinal esperado do coeficiente $\Delta R$ é mais ambíguo, pois uma variação das receitas pode causar aumentos em algumas contas do capital circulante e decréscimos em outras contas. 
Entretanto, como a constante a do modelo é dividida pelos ativos totais da empresa, essa passa a ser uma variável explicativa do modelo, "função inversa dos ativos totais", logo o seu coeficiente é estimado normalmente pela regressão igualmente às demais variáveis. Assim, o modelo não tem intercepto, o que força a regressão passar através da origem, fazendo com que os coeficientes $B$ 's sejam estimadores enviesados de $B$ (real), além de que o cálculo do Coeficiente de Determinação $\left(R^{2}\right)$ necessita da especificação do termo constante, caso contrário, não fica garantida a consistência do valor estimado para $R^{2}$, que inclusive pode assumir um valor que não esteja entre 0 e 1 . (WOOLDRIDGE, 2002, p. 58; GREENE, 2003, p.36). Além do mais, a suposição de que os accruals totais tendem a zero (regressão passando pela origem) é muito restritiva e sem fundamentação teórica econômico-contábil adequada, pois se considera que, devido ao regime de competência adotado pela Contabilidade, o montante do fluxo de caixa dificilmente será igual ao resultado contábil, esperando que haja algum accrual no período.

O modelo KS (KANG \& SIVARAMAKRISHNAN, 1995; p. 353), com o intuito de minimizar os erros nas variáveis, incluí variáveis explicativas que buscam refletir a realidade econômica corrente e que não estão contaminadas devido à utilização de variáveis instrumentais. Por esse modelo, os accruals não-discricionários são estimados através da seguinte regressão:

$$
T A_{i t}=\Phi_{0}+\Phi_{1}\left(\delta_{1} R_{i t}\right)+\Phi_{2}\left(\delta_{2} D_{i t}\right)+\Phi_{3}\left(\delta_{3} P P E_{i t}\right)+\varepsilon_{i t} \text { (Equação 3) }
$$

em que:

$T A_{i t} \quad=$ accruals totais da empresa $i$ no período $t ;$

$R_{i t} \quad=$ receitas líquidas da empresa $i$ no período $t$;

$D_{i t} \quad=$ montante dos custos e despesas operacionais da empresa $i$ no período $t$, excluídas as despesas com depreciação e amortização;

$P P E_{i t} \quad=$ saldo das contas do Ativo Imobilizado e Ativo Diferido (bruto) empresa $i$ no final do período $t$;

$\delta_{1} \quad=C R_{i, t-1} / R_{i, t-1}$

$\delta_{2} \quad=\left(I N V_{i, t-1}+\right.$ DespAntec $\left._{i, t-1}+C P_{i, t-1}\right) / D_{i, t-1}$

$\delta_{3} \quad=\operatorname{Depr}_{i, t-1} / P P E_{i, t-1}$;

$C R_{i-1 t} \quad=$ saldo da conta duplicatas a receber (clientes) da empresa $i$ no período $t-1 ;$

$R_{i, t-1} \quad=$ receitas líquidas da empresa $i$ no período $t-1 ;$

$I N V_{i, t-1}=$ saldo da conta estoques da empresa $i$ no período $t-1$;

DespAntec $_{i, t-1}=$ saldo da conta despesas antecipadas da empresa $i$ no período $t-1$;

$C P_{i, t-1} \quad=$ saldo das contas a pagar no curto prazo da empresa $i$ no período $t-1$;

Depr $_{i, t-1}=$ montante de despesas com depreciação e amortização da empresa $i$ no período $t-1$;

$P P E_{i, t-1} \quad=$ saldo das contas do Ativo Imobilizado e Ativo Diferido (bruto) empresa $i$ no final do período $t-1$;

$\varepsilon_{i t} \quad=$ erro da regressão.

Todas as variáveis são ponderadas pelos ativos totais no início do período $t$. 
Para os dois modelos utilizados, os accruals totais são calculados da seguinte forma:

$$
T A_{i t}=\left(\Delta A C_{i t}-\Delta \operatorname{Disp}_{i t}\right)-\left(\Delta P C_{i t}-\Delta D i v_{i t}\right)-\operatorname{Depr}_{i t} \quad\left(\text { Equação }^{4}\right)
$$

em que:

$T A_{t} \quad=$ accruals totais da empresa no período $t$;

$\Delta A C_{t} \quad=$ variação do ativo corrente (circulante) da empresa no final do período $t-1$ para o final do período $t$;

$\triangle P C_{t} \quad=$ variação do passivo corrente (circulante) da empresa no final do período $t-1$ para o final do período $t$;

$\Delta$ Disp $_{t}=$ variação das disponibilidades da empresa no final do período $\mathrm{t}-1$ para o final do período t;

$\Delta \operatorname{Div}_{t}=$ variação dos financiamentos e empréstimos de curto prazo da empresa no final do período $t-1$ para o final do período $t$;

$\operatorname{Depr}_{t}=$ montante das despesas com depreciação e amortização da empresa durante o período $t$;

Todas as variáveis são ponderadas pelos ativos totais no início do período $t$.

Por fim, os accruals discricionários da empresa $i$ no período $t$, calculadas da seguinte forma:

$$
D A_{i t}=T A_{i t}-N D A_{i t} \quad(\text { Equação } 5)
$$

em que:

$D A_{t} \quad=$ accruals discricionários da empresa no período $t$;

$T A_{t} \quad=$ accruals totais da empresa no período $t$;

$N D A_{t} \quad=$ accruals não-discricionários da empresa no período $t$;

Todas as variáveis são ponderadas pelos ativos totais no início do período $t$.

\subsection{DESENVOLVIMENTO DAS HIPÓTESES}

Com base nas evidências apresentadas em pesquisas anteriores sobre o gerenciamento de resultados em relação à cobertura dos analistas financeiros no âmbito internacional e, levando-se em consideração ainda que o nível de cobertura dos analistas influencia as informações contábeis, podendo inibir a prática discricionária por parte dos gestores das companhias abertas coberturas, têm-se as seguintes hipóteses de pesquisa:

Hipótese 1: O nível de accruals discricionários das companhias abertas brasileiras cobertas pelas empresas de rating é significativamente menor que as companhias nãocobertas.

Hipótese 2: As companhias abertas brasileiras com maior nível de cobertura pelos analistas financeiros apresentam evidências estatísticas de menor nível de accruals discricionários. 
Para confirmar a primeira hipótese levantada nesta pesquisa, espera-se que os accruals discricionários médios das companhias abertas brasileiras cobertas pelas empresas de rating significativamente menores do que as não cobertas, o que sugere um menor nível de gerenciamento de resultados.

Com relação à segunda hipótese, espera-se que as companhias mais monitoradas pelos analistas possuam menor nível de accruals discricionários, sugerindo que quanto maior o nível de cobertura, menor é a prática discricionária das empresas. Neste trabalho, o nível de cobertura das companhias abertas foi mensurado pela quantidade de empresas de rating que as cobrem, considerando assim que a companhia que teve maior cobertura foi aquela que apresentou o maior número de empresas de rating.

Para analisar se os accruals discricionários são significativamente diferentes diante das duas primeiras hipóteses, realizaram-se os testes de hipóteses paramétricos e nãoparamétricos.

E, por fim, diante de sua atividade especializada, existe a possibilidade dos analistas financeiros que atuam nas empresas de rating captarem as práticas discricionárias dos administradores e, conseqüentemente, essa situação refletir negativamente na nota atribuída aos papéis dessas companhias. Então, a terceira hipótese está delineada da seguinte forma:

Hipótese 3: As companhias abertas brasileiras que obtiveram as melhores notas das empresas de rating possuem o menor volume de accruals discricionários.

As notas atribuídas pelas empresas de rating aos títulos públicos das companhias abertas brasileiras foram padronização numa escala de 0 a 100 para a nota de cada empresa de rating, levando em consideração escala de rating e suas subdivisões. A nota final de cada companhia aberta utilizada para análise da terceira hipótese deste trabalho foi a média simples das notas padronizadas atribuídas por cada uma das empresas de rating.

Para comprovar a terceira hipótese deste trabalho, espera-se que os accruals discricionários médios das companhias abertas brasileiras cobertas pelas empresas de rating sejam significativamente proporcionais as notas atribuídas aos títulos negociados publicamente pelas companhias abertas brasileiras.

\section{APRESENTAÇÃO E ANÁLISE DE DADOS}

A Tabela 01 apresenta os parâmetros e as estatísticas dos modelos operacionais para estimação dos accruals discricionários utilizados para detecção de gerenciamento de resultados contábeis nesta pesquisa, através da abordagem pooling of independent cross sections. 
Tabela 01 - Gerenciamento de resultados entre companhias cobertas e não cobertas

\begin{tabular}{|c|c|c|c|c|}
\hline & \multicolumn{2}{|c|}{ Jones } & \multicolumn{2}{|l|}{ KS } \\
\hline & coeficiente & $p$-value & coeficiente & $p$-value \\
\hline Interceptor & & & 0,335 & 0,264 \\
\hline $1 / A_{i-1}$ & $-3642,573$ & 0,146 & & \\
\hline$\Delta \mathrm{R}_{\mathrm{it}}$ & $1,37 \mathrm{E}-05$ & 0,090 & & \\
\hline $\mathrm{PPE}_{\text {it }}$ & $-0,058$ & 0,003 & & \\
\hline$\delta_{1} R_{i t}$ & & & $-0,068$ & 0,916 \\
\hline$\delta_{2} D_{i t}$ & & & $-0,054$ & 0,000 \\
\hline$\delta_{3} P P E_{i t}$ & & & 0,347 & 0,480 \\
\hline$R^{2}$ ajustado & 0,076 & & 0,055 & \\
\hline White Heteroskedasticity Test: & 524,442 & 0,000 & 21,724 & 0,999 \\
\hline $\begin{array}{l}\text { Breusch-Godfrey Serial Correlation LM } \\
\text { Test: }\end{array}$ & 26,283 & 0,000 & 9,398 & 0,009 \\
\hline Jarque-Bera & $1,40 \mathrm{E}+08$ & 0,000 & $1,77 \mathrm{E}+08$ & 0,000 \\
\hline Observações & 2.909 & & 3.051 & \\
\hline
\end{tabular}

Como se pode observar na Tabela 01, os modelos de estimação não têm um bom poder explicativo, sendo que o modelo Jones $\left(R^{2}\right.$ ajustado $\left.=0,076\right)$ possui melhor poder preditivo que o modelo $\mathrm{KS}\left(R^{2}\right.$ ajustado $\left.=0,055\right)$.

Observa-se, também, que os dois modelos apresentam problemas de autocorrelação e de não-normalidade dos resíduos e o modelo Jones ainda possui resíduos heteroscedásticos. Porém, baseado no teorema do limite central, Wooldridge (2002) afirma que os estimadores do método dos Mínimos Quadrados Ordinários (MQO) satisfazem a normalidade assintótica, ou seja, eles aproximadamente têm distribuição normal em amostras de tamanhos suficientemente grandes.

Portanto, apesar de apresentar o teste específico, o pressuposto da normalidade é relaxado nas inferências sobre os parâmetros dos modelos, pois seus coeficientes são consistentes e não-viesados assintoticamente, mesmo na presença de heteroscedasticidade e auto-correlação.

Adicionalmente, com o intuito de verificar a normalidade das variáveis para os testes das primeiras duas hipóteses deste trabalho, foi utilizado o teste K-S (KolmogorovSmirnov) no qual apresentou evidências estatísticas para rejeitar a normalidade dos resultados no período, ou seja, a variável “accruals discricionários" pelos modelos Jones e KS não seguem uma distribuição normal (Tabela 02).

Tabela 02 - Teste de normalidade K-S (Kolmogorov-Smirnov) dos accruals discricionários

\begin{tabular}{|l|l|r|r|}
\hline \multicolumn{2}{|l|}{} & \multicolumn{1}{c|}{ Jones } & \multicolumn{1}{c|}{ KS } \\
\hline Most Extreme Differences & Absolute & 0,319 & 0,311 \\
\hline & Positive & 0,286 & 0,298 \\
\hline & Negative & $-0,319$ & $-0,311$ \\
\hline Kolmogorov-Smirnov Z & & 17,179 & 17,154 \\
\hline$p$-value & 0,000 & 0,000
\end{tabular}

Conforme os resultados apresentados na Tabela 03, não existem evidências de que os accruals discricionários médios calculados pelos modelos utilizados nesta pesquisa sejam 
significativamente diferentes entre as companhias abertas brasileiras cobertas pelas empresas de rating e as não cobertas.

Devido à não-normalidade dos dados nesta pesquisa, foi efetuado o teste nãoparamétrico Kruskal-Wallis para verificar se os accruals discricionários são significativamente diferentes entre as companhias abertas cobertas e não cobertas pelas empresas de rating, pois para esse teste não se faz necessário observar o pressuposto da normalidade dos testes paramétricos (NEWBOLD, CARLSON \& THORNE, 2002; ANDERSON, SWEENEY \& WILLIAMS, 2002).

Tabela 03 - Testes de igualdade dos accruals discricionários médios entre cobertas e não cobertas

\begin{tabular}{l|r|r|}
\multirow{2}{*}{} & \multicolumn{2}{|c|}{ Kruskal Wallis } \\
\cline { 2 - 3 } & statistic & \multicolumn{1}{c|}{$p$-value } \\
\hline Jones & 1,979 & 0,159 \\
\hline KS & 0,126 & 0,723 \\
\hline
\end{tabular}

Conforme os resultados relatados na Tabela 03, não existem evidências de que os accruals discricionários médios calculados pelos modelos utilizados nesta pesquisa sejam significativamente diferentes entre as empresas cobertas e não cobertas pelos analistas financeiros das empresas de rating, não confirmando a primeira hipótese.

Após a análise comparativa entre as empresas cobertas e não cobertas, realizou-se uma análise para verificar se existem diferenças significativas no comportamento dos accruals discricionários das companhias abertas brasileiras cobertas em relação ao nível de cobertura (Hipótese 2). Essa análise seguiu os mesmos procedimentos realizados na análise efetuada na Hipótese 1.

A Tabela 04 apresenta as estatísticas descritivas do conjunto de companhias abertas brasileiras cobertas pelas empresas de rating. 
Tabela 04 - Estatística descritiva dos accruals discricionários por nível de cobertura

\begin{tabular}{|l|r|r|r|r|}
\hline \multirow{4}{*}{ Jones } & Nível de cobertura & N & Média & Desvio Padrão \\
\hline \multirow{3}{*}{} & 1 & 287 & $-0,057$ & 1,499 \\
\cline { 2 - 5 } & 2 & 138 & 0,035 & 0,167 \\
\cline { 2 - 5 } & 3 & 145 & $-0,003$ & 0,160 \\
\cline { 2 - 5 } & 4 & 51 & 0,036 & 0,122 \\
\cline { 2 - 5 } & Total & 621 & $-0,016$ & 1,025 \\
\cline { 2 - 5 } & 1 & 299 & $-0,064$ & 1,433 \\
\cline { 2 - 5 } & 2 & 151 & 0,053 & 0,203 \\
\cline { 2 - 5 } & 3 & 156 & 0,004 & 0,175 \\
\cline { 2 - 5 } & 4 & 55 & 0,037 & 0,112 \\
\cline { 2 - 5 } & Total & 661 & $-0,013$ & 0,973 \\
\hline
\end{tabular}

Como os accruals discricionários não seguem uma distribuição normal, realizou-se o teste não-paramétrico Kruskal-Wallis para verificar se os accruals discricionários são significativamente diferentes entre as companhias abertas cobertas classificadas por nível de cobertura das empresas de rating.

Esses resultados indicam que a segunda hipótese deste trabalho não pode ser confirmada, portanto, não existem diferenças significativas nos accruals discricionários entre as companhias abertas brasileiras classificadas por nível de cobertura das empresas de rating.

Tabela 05 - Testes de igualdade dos accruals discricionários por nível de cobertura

\begin{tabular}{|l|r|r|}
\multirow{2}{*}{} & \multicolumn{2}{|c|}{ Kruskal Wallis } \\
\cline { 2 - 3 } & Statistic & \multicolumn{1}{c|}{$p$-value } \\
\hline Jones & 5,213 & 0,157 \\
\hline KS & 2,585 & 0,460 \\
\hline
\end{tabular}

Buscando maiores evidências sobre as duas primeiras hipóteses desta pesquisa, apesar de os accruals discricionários estimados pelos modelos Jones e KS não serem normalmente distribuídos, realizaram-se, adicionalmente, os testes paramétricos de diferenças entre as médias $F$ ANOVA, Welch e Brown-Forsythe, sendo que os dois últimos são preferíveis quando o pressuposto da homogeneidade das variâncias não é observado (MERINO \& DÍAZ, 2002). Os resultados desses testes corroboram as evidências encontradas pelo teste não-paramétrico Kruskal-Wallis apresentadas anteriormente, sendo suprimidos deste texto por conta da limitação de páginas.

Complementarmente, todas as análises anteriores foram efetuadas com base no desvio-padrão dos accruals discricionários de cada empresa. Considera-se que as empresas que possuem maior desvio-padrão nos accruals discricionários são aquelas que têm maior 
probabilidade de gerenciamento de resultados contábeis. A utilização do desvio-padrão dos accruals discricionários, em vez do montante dos accruals discricionários, como medida de gerenciamento de resultados contábeis deve-se ao fato de que um maior volume de accruals (discricionários e não-discricionários) pode ser ocasionado pelas características particulares de cada empresa.

Os resultados dos testes com os desvios dos accruals discricionários foram suprimidos deste trabalho pelo mesmo motivo exposto anteriormente. Novamente, as evidências apresentadas com os desvios dos accruals discricionários confirmam os resultados anteriores.

Por fim, com o intuito de analisar a terceira e última hipótese levantada nesta pesquisa, as notas atribuídas pelas empresas de rating foram padronizadas numa escala de 0 a 100 e, após esse procedimento, calculou-se a nota de rating média de cada companhia aberta brasileira coberta. Efetuaram-se as análises de correlação de Pearson e de Sperman's, entre a nota de rating média de cada companhia aberta e seu respectivo volume de accruals discricionários médios (Tabela 06).

Tabela 06 - Análise de correlação entre as notas de rating e os accruals discricionários

\begin{tabular}{|l|l|r|r|}
\hline \multirow{3}{*}{ Jones } & & Pearson & \multicolumn{1}{|c|}{ Spearman } \\
\hline \multirow{3}{*}{ KS } & statistic & 0,001 & $-0,023$ \\
\cline { 2 - 4 } & $p$-value (2-tailed) & 0,987 & 0,564 \\
\cline { 2 - 4 } & $N$ & 621 & 621 \\
\hline & statistic & $-0,007$ & $-0,059$ \\
\cline { 2 - 4 } & $p$-value (2-tailed) & 0,854 & 0,128 \\
\cline { 2 - 4 } & $N$ & 661 & 661 \\
\hline
\end{tabular}

Ambos os testes indicam que não existem correlação significativa entre as notas de rating médias e accruals discricionários das companhias abertas brasileiras. Essa evidência não confirma a terceira hipótese dessa pesquisa.

\section{CONSIDERAÇÕES FINAIS}

Este trabalho buscou compreender a relação entre as informações contábeis divulgadas pelas companhias abertas brasileiras e as atividades dos analistas financeiros ligados às empresas de rating. Torna-se relevante avaliar tal relação, pois os analistas financeiros desempenham uma atividade importante no mercado financeiro, através da atribuição de uma nota de rating para os títulos negociados no mercado nacional.

Com base nas análises realizadas nesta pesquisa, não se pode afirmar que existem diferenças significativas entre os accruals discricionários entre as companhias abertas brasileiras cobertas pelas empresas de rating e as não cobertas, ou seja, não apresentam níveis diferentes de gerenciamento de resultados contábeis entre esses dois grupos de companhias (cobertas e não cobertas).

Os resultados desta pesquisa também mostram que não existe relação significativa entre o comportamento oportunístico e o nível de cobertura das empresas de rating no mercado brasileiro. Adicionalmente, não foi verificada nenhuma relação entre o rating atribuído aos títulos das companhias abertas e o comportamento dos accruals discricionários. 
As evidências empíricas apresentadas nesta pesquisa podem sugerir que:

- As companhias abertas brasileiras não se preocupam como rating a ser atribuído aos seus papéis é afetado pelas práticas oportunísticas de gerenciamento de resultados através dos accruals contábeis;

* Os analistas financeiros das empresas de rating não observam o comportamento discricionário das empresas no momento da avaliação de seus papéis negociáveis;

- Os analistas financeiros das empresas de rating não conseguem identificar os accruals discricionários adequadamente e, conseqüentemente, não detectam o gerenciamento de resultados contábeis das empresas;

- Os modelos utilizados para a segregação dos accruals discricionários e não discricionários não conseguem avaliar adequadamente o comportamento dos accruals.

Esta pesquisa teve como principais limitações o reduzido número de empresas de rating atuantes no mercado brasileiro que disponibilizaram as informações necessárias e o pequeno número de companhias abertas cobertas.

Para futuros estudos, sugere-se avaliar a influência da cobertura dos analistas financeiros que atuem em outros tipos de empresas ligadas ao mercado financeiro e de capitais. Também, devido às evidências de baixo poder preditivo dos modelos utilizados, torna-se relevante utilizar outros modelos constantes na literatura corrente, bem como desenvolver novos, para verificar se corroboram as evidências apresentadas neste estudo.

\section{REFERÊNCIAS}

ANDERSON, David R.; SWEENEY, Dennis J.; WILLIAMS, Thomas A. Statistics for business and economics. 8. ed. Ohio: Thomson Learning, 2002.

BEAVER, William H. Financial reporting: an accounting revolution. $3^{\text {rd }}$ ed. New Jersey: Prentice Hall, 1998.

BENEISH, Messod D. Earnings management: a perspective. Managerial Finance. v. 27. 12. 2001. p.3-18.

BEUREN, Ilse Maria (Org.). Como elaborar trabalhos monográficos em contabilidade: teoria e prática. São Paulo: Atlas, 2003.

FIELDS, Thomas D.; LYS, Thomas Z.; VINCENT, Linda. Empirical research on accounting choice. Journal of Accounting and Economics. New York: v. 31, 1-3, p. 255-307, sep. 2001.

FORTUNA, Eduardo. Mercado financeiro: produtos e serviços. 16. ed. Rio de Janeiro: Qualitymark, 2005.

GREENE, William H. Econometric analysis. 5.ed. New Jersey: Prentice Hall, 2003.

HEALY, Paul M.; WAHLEN, James M. A review of the earnings management literature and its implications for standard setting. Accounting Horizons. v. 13. 4. 1999. p.365-383.

; PALEPU, Krishna G. Information asymmetry, corporate disclosure, and the capital markets: a review of the empirical disclosure literature. Journal of Accounting and Economics. New York: v. 31, 1-3, p. 405-440, sep. 2001. 
JENSEN, Michael C. A theory of the firm: governance, residual claims, and organizational forms. Massachesetts: Harvard University Press, 2001.

JONES, Jeniffer J. Earnings management during import relief investigations. Journal of Accounting Research. Oxford: v. 29, 2, p.193-228, autumn, 1991.

KANG, Sok-Hyon.; SIVARAMAKRISHNAN, K. Issues in testing earnings management and an instrumental variable approach. Journal of Accounting Research. Oxford: v. 33, 2, p. 353367, autumn, 1995.

MARTINEZ, Antonio Lopo. Gerenciamento dos resultados contábeis: estudo empírico das companhias abertas brasileiras. São Paulo, 2001. Tese (Doutorado em Ciências Contábeis). Universidade de São Paulo - Faculdade de Economia Administração e Contabilidade. São Paulo, 2001.

MARTINS, Eliseu. Contabilidade versus fluxo de caixa. Caderno de Estudos da Fipecafi. São Paulo: Fipecafi, 20, jan.-abr., 1999, p. 1-10.

PALEPU, Krishna G.; HEALY, Paul M.; BERNARD, Vitor L. Business analysis e valuation: using financial statements. $3^{\text {rd }}$ ed. Ohio: Thomson Learning, 2004.

PAULO, Edilson; LIMA, Gerlando Augusto S. F.; LIMA, Iran Siqueira. A influência dos analistas financeiros sobre 0 gerenciamento de resultados das companhias abertas brasileiras. In: CONGRESSO USP DE CONTROLADORIA E CONTABILIDADE, 8, 2006, São Paulo. Anais... São Paulo: FEA/USP, 2006. CD-ROM.

PEASNELL, Ken V.; et al. Detecting earnings management using cross-sectional abnormal accruals models. Accounting and Business Research. London: v. 30, 4, p.313-326, autumn 2000.

RAJAN, Raghuram; SERVAES, Henri. Analyst following of initial public offerings. Journal of Finance. Oxford: v. 52, 2, p.507-529, jun. 1997.

SCOTT, William R. Financial accounting theory. $3^{\text {rd }}$ ed. Toronto: Prentice Hall, 2003.

SILVA, José Pereira da. Análise financeira das empresas. 5. ed. São Paulo: Atlas, 2006.

TEOH, Siew Hong; WONG, T. J. Analysts' credulity about reported earnings and overoptimism in new equity issues. Working paper: Ohio State University, 1997. Disponível em: <http: //www.ssrn.com>. Acesso em: 27 fev. 2006.

WOOLDRIDGE, Jeffrey M. Introductory econometrics: a modern approach. $2^{\text {nd }}$ ed. Ohio: South-Western College Pub, 2002.

YU, Frank. Analyst coverage and earnings management. Working Papers. University of Minessota, feb., 2005. Disponível em: <http://www.ssrn.com>. Acesso em: 03 dez 2005. 